\title{
Application of Micro-Teaching in the Training of Intravenous Indwelling Needle Infusion for Clinical Nursing Students
}

\author{
Yonghao You1, Rongting Liu ${ }^{2 *}$ \\ ${ }^{1}$ Department of Surgery, The First Affiliated Hospital of Yangtze University, Jingzhou, China \\ ${ }^{2}$ Department of Gastrointestinal Surgery, The First Affiliated Hospital of Yangtze University, Jingzhou, China \\ Email: *6517401@qq.com
}

How to cite this paper: You, Y.H. and Liu, R.T. (2019) Application of Micro-Teaching in the Training of Intravenous Indwelling Needle Infusion for Clinical Nursing Students. Yangtze Medicine, 3, 176-182. https://doi.org/10.4236/ym.2019.33018

Received: November 13, 2018

Accepted: June 25, 2019

Published: June 28, 2019

Copyright () 2019 by author(s) and Scientific Research Publishing Inc. This work is licensed under the Creative Commons Attribution International License (CC BY 4.0).

http://creativecommons.org/licenses/by/4.0/

\begin{abstract}
Objective: To explore the application effect of micro-teaching in the training of intravenous indwelling needle for clinical nursing students. Methods: A total of 102 undergraduate nursing students who were interned in our department from July 2016 to February 2018 were assigned randomly to the experimental group and the control group, 51 for each. The traditional teaching method was used in the control group for the training of intravenous indwelling needle infusion skills, whereas the micro-teaching method was used in the experimental group. Before the end of the internship, the two groups of interns were given a score test of intravenous indwelling needle infusion skills and an anonymous questionnaire survey on teaching effects. Results: The results of the skill test showed that the total scores of the control group and the experimental group were $(76.73 \pm 1.67)$ and $(84.12 \pm 1.90)$, respectively, and the difference was statistically significant $(\mathrm{p}<0.01)$. According to the questionnaire survey, the percentage of the students in experimental group who had a positive attitude toward teaching methods, interest in learning, self-learning ability, and learning efficiency, was higher than that in the control group, and there was a statistical significance $(\mathrm{p}<0.05)$. Conclusion: Microteaching can effectively promote the nursing students' mastery of intravenous indwelling needle infusion skills, stimulate interest in learning, improve self-learning ability, improve learning efficiency and achieve satisfactory teaching effects.
\end{abstract}

\section{Keywords}

Microteaching, Nursing, Intravenous Indwelling Needle, Intravenous Infusion 


\section{Introduction}

Intravenous indwelling needle, also known as trocar, as a substitute for scalp needle, has the advantages such as reducing the number of vascular punctures, reducing the workload of nurses, reducing patient suffering and improving the efficiency of nursing work. It can quickly pierce the skin, safe and easy to operate and fix with little irritation, and has been widely used in clinical practice. As one of the basic nursing operations, venous catheterization is also a must for nursing students in clinical practice. Microteaching, formed in the American education reform movement in the 1960s, is a kind of miniaturized teaching which uses the recording equipment to record the trainee's practice process and train the their professional skills through the feedback of the principle and the evaluation of the theory [1]. In 2017, our department applied the micro-teaching method to the training of intravenous indwelling needle infusion for clinical nursing students, and achieved good results. The report is as follows.

\section{Method Part}

\subsection{General Data}

A total of 102 undergraduate nursing students who were interned in our department from July 2016 to February 2018, and aged 19 to 22 with a median age of 21 years, were assigned randomly to the experimental group and the control group, 51 for each. The traditional teaching method was used in the control group for the training of intravenous indwelling needle infusion skills, whereas the micro-teaching method was used in the experimental group. This study has been approved by the Ethics Committee of Affiliated Hospital of Yangtze University. There was no significant difference in the ages and gender ratios between the two groups $(\mathrm{P}>0.05)$.

\subsection{Methods}

\subsubsection{Teaching Methods}

In the control group, the traditional teaching method was adopted, and the senior nurse of our department served as the clinical teacher to train the intravenous indwelling needle infusion skills by means of theoretical teaching, operation demonstration and nursing practice. Meanwhile, the micro-teaching method was used in the experimental group. After the theoretical teaching and operation demonstration of the clinical teacher, the whole operation process of the nursing students was taken by the smart phone. Students reviewed the video to perform self-evaluation or mutual evaluation between themselves, and finally the clinical teacher summarized and analyzed. In this way, the problems are found, fed back and corrected to achieve the teaching effects. All nursing students were trained for 3 days.

\subsubsection{Assessment of Teaching Effects}

Before the end of the internship in our department, the officer-in-charge gave 
the nursing students a score test of intravenous indwelling needle infusion skills and an anonymous questionnaire survey on teaching effects. In the assessment, the rating rules were formulated from the aspects of theoretical knowledge, preparation of items, sterile operation, selection of puncture site, angle and speed of needle insertion, technique of pushing sleeve, technique of withdrawing needle, method of sealing catheter, method of flushing catheter and indwelling needle removal, 10 points for each rule. The total score was set to 100 points. We adopted a self-designed anonymous questionnaire to understand the evaluation of nurse students on training and teaching. After the end of the examination, the questionnaire was issued and collected on the spot, with an effective recovery rate of $100 \%$. The questionnaire survey included contents such as teaching methods, interest in learning, self-learning ability and learning efficiency. Students made "affirmative" or "negative" evaluations, and the teaching effect was evaluated based on the feedback from the questionnaire survey.

\subsection{Statistical Methods}

Statistical analysis was performed using SPSS19.0 software. The measurement data were expressed as $\bar{X} \pm s$, and the t test was used. The count data were analyzed by $\chi^{2}$ test. $\mathrm{p}<0.05$ showed that the difference was statistically significant.

\section{Results}

The assessment results showed that the total scores of the control group and the experimental group were $(76.73 \pm 1.67)$ and $(84.12 \pm 1.90)$, respectively, and the difference was statistically significant $(\mathrm{p}<0.01)$ (Table 1$)$. According to the questionnaire survey on teaching methods, the percentage of students in experimental group who had a positive attitude towards teaching methods, interest in learning, self-learning ability and learning efficiency was higher than that in the control group. The difference was statistically significant $(\mathrm{p}<0.05)$ (Table 2$)$.

\section{Discussion}

Medical education is an important stage and learning process for the growth of medical and health personnel. Due to the influence of multiple factors such as society, economy and education, most of the medical education in China currently adopts the traditional teaching method, that is, teachers teach students face to face, students passively accept the knowledge, and the assessment is performed finally. In the skills training for the clinical nursing students, the clinical teacher first conducts text explanations and operation demonstrations in accordance with the standard operating specification, and then students carry out their own practice after reading the relevant books and mastering the basic principles. The medical skill operation is complex and boring, so many nursing students lack learning interest and enthusiasm. They only passively accept the indoctrinating knowledge from teachers, lack of mutual inspiration, discussion 
Table 1. Comparison of the assessment results between two groups of students $(\bar{X} \pm s$, points).

\begin{tabular}{|c|c|c|c|c|}
\hline & Experimental group $(\mathrm{n}=51)$ & Control group $(\mathrm{n}=51)$ & $\mathrm{t}$ & $\mathrm{p}$ \\
\hline Theoretical knowledge & $8.08 \pm 0.69$ & $8.04 \pm 0.72$ & 0.281 & 0.779 \\
\hline Preparation of items & $8.14 \pm 0.75$ & $7.92 \pm 0.72$ & 1.486 & 0.140 \\
\hline Sterile operation & $8.69 \pm 0.58$ & $7.49 \pm 0.64$ & 9.834 & 0.000 \\
\hline Selection of puncture site & $8.51 \pm 0.58$ & $7.73 \pm 0.72$ & 6.047 & 0.000 \\
\hline $\begin{array}{l}\text { Angle and speed } \\
\text { of needle insertion }\end{array}$ & $8.61 \pm 0.53$ & $7.71 \pm 0.54$ & 8.495 & 0.000 \\
\hline $\begin{array}{l}\text { Technique of } \\
\text { pushing sleeve }\end{array}$ & $8.33 \pm 0.59$ & $7.45 \pm 0.50$ & 8.140 & 0.000 \\
\hline $\begin{array}{c}\text { Technique of } \\
\text { withdrawing needle }\end{array}$ & $8.45 \pm 0.54$ & $7.65 \pm 0.59$ & 7.146 & 0.000 \\
\hline $\begin{array}{c}\text { Method of } \\
\text { sealing catheter }\end{array}$ & $8.57 \pm 0.50$ & $7.67 \pm 0.48$ & 9.328 & 0.000 \\
\hline $\begin{array}{l}\text { Method of } \\
\text { flushing catheter }\end{array}$ & $8.41 \pm 0.54$ & $7.51 \pm 0.51$ & 8.750 & 0.000 \\
\hline $\begin{array}{c}\text { Indwelling } \\
\text { needle removal }\end{array}$ & $8.33 \pm 0.55$ & $7.57 \pm 0.54$ & 7.069 & 0.000 \\
\hline Total score & $84.12 \pm 1.90$ & $76.73 \pm 1.67$ & 20.820 & 0.000 \\
\hline
\end{tabular}

Table 2. Comparison of the questionnaire survey results between two groups of students.

\begin{tabular}{ccccccc}
\hline & \multicolumn{2}{c}{ Experimental group $(\mathrm{n}=51)$} & \multicolumn{2}{c}{ Control group $(\mathrm{n}=51)$} & & \\
\cline { 2 - 5 } & $\begin{array}{c}\text { Number of } \\
\text { students with } \\
\text { affirmative } \\
\text { evaluation }\end{array}$ & $\begin{array}{c}\text { Percentage } \\
(\%)\end{array}$ & $\begin{array}{c}\text { Number of } \\
\text { students with } \\
\text { affirmative } \\
\text { evaluation }\end{array}$ & $\begin{array}{c}\text { Percentage } \\
(\%)\end{array}$ & $\chi^{2}$ & $\mathrm{p}$ \\
\cline { 1 - 4 } $\begin{array}{c}\text { Teaching } \\
\text { method }\end{array}$ & 49 & 96.08 & 40 & 78.43 & 7.141 & 0.008 \\
$\begin{array}{c}\text { Interest } \\
\text { in learning }\end{array}$ & 48 & 94.12 & 41 & 80.39 & 4.320 & 0.038 \\
$\begin{array}{c}\text { Self-learning } \\
\text { ability }\end{array}$ & 50 & 98.04 & 39 & 76.47 & 10.667 & 0.001 \\
$\begin{array}{c}\text { Learning } \\
\text { efficiency }\end{array}$ & 48 & 94.12 & 40 & 78.43 & 5.299 & 0.021 \\
\hline
\end{tabular}

and deeper thinking exchange between teachers and students [2]. At the same time, the clinical practice opportunities for nursing students are very limited due to the current domestic medical environment. Therefore, the traditional teaching method is difficult to stimulate the initiative, creativity, enthusiasm and potential of nursing students [3].

In recent years, with the introduction and practice of the new forms of teaching methods such as micro-teaching, it has been proved to have better effects than the traditional teaching method [4] [5]. Micro-teaching has been translated 
into several Chinese versions, but its main feature is to use video, audio and other means to collect the student's operation process, and then play back and analyze it so that the educated student can have a comprehensive, intuitive and in-depth understanding of its own image, and analyze and evaluate from students themselves, other students, teachers and other different perspectives, but also enable educators to fully understand the situation of each student, perform the assessment, analyze the evaluation and guide the training to achieve the best teaching effect [6]. The advantage of micro-teaching is that on the one hand, the complexity of teaching is reduced. The simulated teaching environment can reduce the psychological pressure caused by real teaching, and students can intuitively find their deficiencies in detail. On the other hand, micro-teaching is a self-exploratory teaching form based on the students. All members participate in the training during the teaching process, and each one is both a trainee and a trainer. Therefore, it is beneficial to improve the enthusiasm of all members and improve their evaluation ability. Based on the advantages of micro-teaching, combined with the actual situation of our department, we adopt the micro-teaching mode to train our nursing students in intravenous infusion needle infusion skills, and have achieved remarkable teaching effects.

Compared with the traditional teaching method, the micro-teaching mode is basically a training method of information feedback, which has strong adaptability in the teaching practice of skill training [7]. When implementing micro-teaching, the clinical teacher uses the video to repeatedly watch and study each small operation detail with students, and they make immediate feedback, so that students practice and improve. Students are allowed and encouraged to ask questions and clarify questions. Teachers hint with positive words to increase student participation in the development of the teaching process. The results of this study showed that the test results of intravenous indwelling needle infusion skills of the experimental group were significantly better than those of the control group $(\mathrm{P}<0.01)$, indicating that the implementation of micro-teaching can improve the ability of nursing students to perform intravenous needle infusion.

It has been shown in the literature that constructive feedback among students in micro-teaching plays a crucial role in the acquisition and improvement of skills [8]. The process of learning together in social media can strengthen their self-confidence and stimulate their potential learning motivation [9]. In this study, the micro-teaching method enables nursing students to listen, observe and practice as much as possible while learning skills. The popularity of smart phones makes it easy for students to use their video capture function to more intuitively and specifically review the whole learning process. In the process, the problems are found and solved, which simulates students' interest in learning, promotes them to actively gain the knowledge and makes the learning process no longer boring. Students can even share the video of learning process through the WeChat group to achieve mutual evaluation between students and teachers and students. The results of this study showed that the percentage of the stu- 
dents in the experimental group who had a positive attitude toward teaching methods, interest in learning, self-learning ability and learning efficiency was higher than that in the control group $(\mathrm{P}<0.05)$, indicating that micro-teaching may improve the traditional nursing teaching mode which is boring and mechanical, make the teaching more flexible and vivid, and more easily stimulate the interest of learning and cultivate self-learning ability, thus improving the learning efficiency of nurse students and facilitating its promotion in future nursing teaching.

\section{Conclusion}

In summary, through the use of micro-teaching, we have effectively promoted the nursing students' mastery of intravenous indwelling needle infusion skills, stimulated their interest in learning, improved their self-learning ability, improved their learning efficiency and achieved satisfactory teaching effects.

\section{Funding}

This research received no specific grant from any funding agency in the public, commercial, or not-for-profit sectors.

\section{Conflicts of Interest}

The authors declare that there are no conflicts of interest.

\section{References}

[1] Yang, G., Wang, P. and Tang, L. (2012) Application of Microteaching in Nurses' Pre-Hospital Emergency Skills Training. Chinese General Practice Nursing, 10, 80-81.

[2] Remesh, A. (2013) Microteaching, an Efficient Technique for Learning Effective Teaching. Journal of Research in Medical Sciences the Official Journal of Isfahan University of Medical Sciences, 18, 158-163.

[3] Crosby, M.H. (1977) Teaching Strategies: A Microteaching Project for Nurses in Virginia. Nursing Research, 26, 144-147. https://doi.org/10.1097/00006199-197703000-00021

[4] Singh, T. (2011) Microteaching Revisited. National Medical Journal of India, 24, 363-364.

[5] Peker, M. (2009) The Use of Expanded Microteaching for Reducing Preservice Teachers' Teaching Anxiety about Mathematics. Eurasia Journal of Mathematics, Science and Technology Education, 4, 872-880. https://doi.org/10.12973/ejmste/75284

[6] Brent, R., Wheatley, E.A. and Thomson, W.S. (1996) Videotaped Microteaching: Bridging the Gap from the University to the Classroom. The Teacher Educator, 31, 238-247. https://doi.org/10.1080/08878739609555115

[7] Li, L. (2016) Application of Microteaching in Table Tennis Technical Teaching. Journal of Wuhan Institute of Physical Education, 32, 207-209.

[8] Najma, B., Usman, M. and James, D. (2017) Micro-Feedback Training: Learning the Art of Effective Feedback. Pakistan Journal of Medical Sciences, 33, 1525-1527. 
https://doi.org/10.12669/pjms.336.13721

[9] Kalyanasundaram, M., Abraham, S.B., Ramachandran, D., et al. (2017) Effectiveness of Mind Mapping Technique in Information Retrieval among Medical College Students in Puducherry: A Pilot Study. Indian Journal of Community Medicine Official Publication of Indian Association of Preventive \& Social Medicine, 42, 19-23. https://doi.org/10.4103/0970-0218.199793 